\title{
Prevalence of Tuberculosis and Treatment Outcomes of Patients with Tuberculosis among Inmates in Debrebirhan Prison, North Shoa Ethiopia
}

\author{
Yonas Asres Berihun ${ }^{1}$, Teklehaimanot Mezgebe Nguse $^{2^{*}}$, Gebremedhin \\ Beedemariam Gebretekle ${ }^{3}$
}

\footnotetext{
OPEN ACCESS

Citation: Yonas Asres Berihun, Teklehaimanot Mezgebe Nguse, Gebremedhin Beedemariam Gebretekle. Prevalence of Tuberculosis and Treatment Outcomes of Patients with Tuberculosis among Inmates in Debrebirhan Prison, North Shoa Ethiopia. Ethiop J Health Sci.2017;28(3):347.

doi:http://dx.doi.org/10.4314/ejhs.v28i3.13

Received: December 9, 2017

Accepted: December 16, 2017

Published: May 1, 2018

Copyright: (C) 2018 Yonas Asres Berihun, et al . This is an open access article distributed under the terms of the Creative Commons Attribution License, which permits unrestricted use, distribution, and reproduction in any medium, provided the original author and source are credited.

Funding: Nil

Competing Interests: The authors declare that this manuscript was approved by all authors in its form and that no competing interest exists.

Affiliation and Correspondence:

${ }^{1}$ Federal Prisons Administration, Addis Ababa, Ethiopia ${ }^{2}$ School of Medicine, College of Health Sciences, Addis Ababa University, Ethiopia

${ }^{3}$ School of Pharmacy, College of Health Sciences, Addis Ababa University, Ethiopia

*Email: cumeltekle@gmail.com
}

\section{ABSTRACT}

BACKGROUND: Prevalence of tuberculosis in vulnerable groups such as prisoners is usually high, and the problem is worsened by poor treatment outcomes. In spite of this, there is limited information regarding tuberculosis in prisons of Ethiopia. Hence, this study was aimed to assess the prevalence of tuberculosis and treatment outcomes of patients with tuberculosis among inmates of Debrebirhan prison in North Shoa, Ethiopia.

METHODS: $A$ retrospective cross-sectional study was conducted among inmates of Debrebirhan prison. Data were collected by reviewing the medical charts and other records of prison inmates diagnosed and treated for tuberculosis between September 2010 and August 2015. Data were entered and analyzed using SPSS version 21.0.

RESULTS: A total of 162 patients with tuberculosis were registered and treated at Debrebirhan prison health center within the five years study period. The overall average prevalence was found to be 32 per 1538 (2139 per 100,000) prison inmates. Regarding treatment outcome, 44(27.2\%) were cured, 59(36.42\%) completed treatment, 2(1.24\%) were treatment failures, 6(3.72\%) died and 51(31.5\%) were not evaluated. The five year's treatment success rate was found to be $63.62 \%$. Area of residence $(A O R=3.59 ; 95 \%$ CI: 1.44, 8.93), duration of imprisonment (AOR $=3.67$; 95\% CI: $1.53,8.78)$ and history of tuberculosis were significantly associated with treatment outcome of tuberculosis.

CONCLUSION: This study showed high prevalence of tuberculosis in Debrebirhan prison. It also revealed that the treatment success rate of patients with tuberculosis was lower than the target set by World Health Organization.

KEYWORDS: Tuberculosis, Treatment outcome, Prevalence, Prison, Inmates, Ethiopia 


\section{INTRODUCTION}

Despite the availability of efficacious drugs, tuberculosis (TB) remains a major public health problem in low and middle income countries. Ninety-five percent of the global TB disease and TB death burden is found in poor countries of Africa and Eastern Europe. More than $80 \%$ of the global TB cases are found in 22 high burden countries (HBCs), including Ethiopia (1-3). According to the 2015 world health organization (WHO) global TB report, Ethiopia ranked seventh in the list of HBCs for TB, with an estimated prevalence of 200 cases per 100,000 persons and mortality rate of 32 per 100,000 (1). The situation is worsened in prison populations with a very high prevalence ranging from 5 to 70 times higher than in the general population (4).

The overall prevalence of smear positive pulmonary tuberculosis (PTB) infection was 5.3\% $(15 / 282)$ in prison settings of North Gondar Zone (5). In a survey conducted in Hadiya Zone prison, the point prevalence of smear positive PTB was 349.2 per 100,000 populations, about three times higher than in the general population (6). Cognizant of the burden of TB, countries like Ethiopia have given due attention to the control of TB by including the prevention and control of the case among the priority health programs aligning with the global plan to stop TB (7).

Treatment outcome is an important indicator to evaluate the effect of TB prevention and control program (1). Globally, in 2012, the treatment success rate was $86 \%$ among all new TB cases and in the African region, it was $81 \%$. Of the 22 HBCs, 15 reached or exceeded a treatment success rate of $85 \%$ among all new cases in 2012. In Ethiopia, treatment success rate for all new and relapse cases was $91 \%$ in 2012 and $89 \%$ in 2013 $(1,2)$.

Among the 244 patients who received treatment, $77 \%$ were cured, $5 \%$ died, $7 \%$ failed, and $12 \%$ defaulted (8). In a study conducted in Debre Berhan Hospital, 1016(79.4\%) had successful treatment outcome. Of these, 203(20\%) and $813(80 \%)$ patients were cured and treatment completed, respectively (9). A retrospective study conducted in selected health facilities of Afar Regional State, Ethiopia, reported a treatment success of $81.8 \%(10)$.

Hence, TB control programs should give emphasis towards prison health systems so as to increase case detection rate of TB and strengthen Direct Observation Therapy (DOT) program to improve the treatment success rate and to establish efficient referral and contact tracing mechanisms for transferred out cases (11). However, there is scarcity of information on prison health in Ethiopia and especially in the selected prison center (12). Therefore, this study was aimed to assess the prevalence of tuberculosis and treatment outcomes of tuberculosis among inmates of Debrebirhan prison, North Shoa, Ethiopia.

\section{MATERIALS AND METHODS}

Study area and setting: The study was conducted in a prison which is located in Debrebirhan city, central Ethiopia, North Shoa Zone of Amhara Region, which is about $130 \mathrm{~km}$ Northeast of Addis Ababa. Debrebirhan prison is one of the 30 prisons in Amhara Regional State of Ethiopia. There were 1,692 (1,660 males and 32 females) prisoners during the data collection period which was between September 2010 and August 2015. The prison has a health center which provides basic curative and preventive health services to the prison inmates and the prison staff. It also provides TB diagnostic and treatment services.

Study design: A retrospective cross-sectional study was conducted by reviewing the existing data of the prison inmates diagnosed and treated for tuberculosis between September 2010 and August 2015. All inmates of Debrebirhan prison were the source population, and all inmates of the prison who were on anti-tuberculosis during the study period were included in the study.

Data collection and management: A data abstraction sheet was designed for collecting data of patients with TB who were included in the study. Medical charts like symptomatic TB screening registers, health management information system registers and laboratory registers were reviewed thoroughly to collect data

DOI: http://x.doi.org/10.4314/ejhs.v28i3.13 
on age, sex, Human Immunodeficiency Virus (HIV) status, type of TB diagnosed, previous TB history and treatment outcomes of TB. Additional data such as residence, educational status, duration of stay in prison and number of prisoners were obtained from the prisoners' profiles kept in the prisoners' administrator office. Data was collected by a trained clinical nurse between March 01, 2016 and April 30, 2016. To ensure the quality of data collected, regular supervision was performed.

Data entry and analysis: Before entry, data were coded and cleaned for consistency and completeness. The data was entered and analyzed using Statistical Package for Social Sciences (SPSS) version 21.0. Descriptive statistics including mean, percentage and standard deviations were computed for the survey data. Multivariable logistic regression was used to explore possible associations between the treatment outcome and other independent variables.

Measurement: In this study, tuberculosis treatment outcome was dichotomized as successful treatment outcome (cured or treatment completed) or poor treatment outcome (treatment failure or death or not evaluated or transferred out). The following operational definitions were adapted (9).

- Cured: patients whose sputum smear or culture was positive at the beginning of the treatment but smear or culture negative in the last month of treatment and on at least one previous occasion.

- Treatment completed: patient who completed treatment without evidence of failure but with no record to show that sputum smear or culture results in the last month of treatment and on at least one previous occasion were negative.

- Treatment failure: patients whose sputum smear or culture was positive at the fifth month or later during treatment.

- Not evaluated: patient for whom no treatment outcome is assigned. This includes cases 'transferred-out' to another treatment unit as well as cases for whom the treatment outcome is unknown to the reporting unit.
- Died: patient who dies for any reason during the course of treatment.

Ethical considerations: Ethical clearance of the study was granted from the Ethical Review Board of Africa Medical College (protocol number: MPH/AF-026/2016). Permission to conduct the research was also sought from the prison administrator. To maintain confidentiality and anonymity, data collector was recruited from the health center. There was no use of individual identifiers and the data obtained from the records were only accessed by the investigators.

\section{RESULTS}

Socio-demographic and clinical characteristics: The total number of inmates in Debrebirhan prison during the five years period was 7691, ranging from 1203 prisoners in $2010 / 11$ to 1701 in $2013 / 14$, with a mean (for all the five years period) of 1538 prisoners. Of these, a total of 162 TB patients were registered at the prison health center between September 2010 and August 2015. Although there were few female prisoners, all of the 162 TB patients were males with mean age of $30.2+9.77$ years, ranging between 15 and 56 years. More than one-third $(37.65 \%)$ of the patients were within the age category of 25-34 years. Regarding their area of residence prior to their imprisonment, $97(59.88 \%)$ of the patients were rural residents (Table 1).

Most $(92.6 \%)$ of the patients were new TB cases, but there were also $3(1.9 \%)$ relapses and $7(4.3 \%)$ transferred-in cases. Looking into the type of $\mathrm{TB}$, the majority, $73(45.1 \%)$, of the patients were smear positive pulmonary TB followed by smear negative pulmonary TB patients, 66(40.7\%). One hundred and fourteen (70.4\%) of the TB patients were tested for HIV and 6 of them were found to be positive resulting in a HIV-prevalence of $3.7 \%$ among TB cases (Table 1).

DOI: http://dx.doi.org/10.4314/ejhs.v28i3.13 
Table 1: Socio-demographic and clinical characteristics of patients with TB in Debrebirhan prison, North Shoa Ethiopia; September 2010 August $2015(\mathrm{n}=162)$

\begin{tabular}{|c|c|c|}
\hline Variables & Frequency & Percent \\
\hline \multicolumn{3}{|l|}{ Sex } \\
\hline Male & 162 & 100.0 \\
\hline \multicolumn{3}{|l|}{ Age group (in years) } \\
\hline $15-24$ & 52 & 32.10 \\
\hline $25-34$ & 61 & 37.65 \\
\hline $35-44$ & 30 & 18.52 \\
\hline$\geq 45$ & 19 & 11.73 \\
\hline \multicolumn{3}{|l|}{ Residence } \\
\hline Rural & 97 & 59.88 \\
\hline Urban & 65 & 40.12 \\
\hline \multicolumn{3}{|l|}{ Educational Status } \\
\hline Below grade 5 & 76 & 46.9 \\
\hline Grades 5-10 & 70 & 43.2 \\
\hline Above grade 10 & 16 & 9.9 \\
\hline \multicolumn{3}{|c|}{ Duration of Imprisonment } \\
\hline$\leq 2$ years & 66 & 40.74 \\
\hline$>2$ years & 96 & 59.26 \\
\hline \multicolumn{3}{|l|}{ HIV Status } \\
\hline Positive & 6 & 3.7 \\
\hline Negative & 108 & 66.7 \\
\hline Unknown & 48 & 29.6 \\
\hline \multicolumn{3}{|l|}{ Patient Category } \\
\hline New & 150 & 92.6 \\
\hline Relapse & 3 & 1.9 \\
\hline $\begin{array}{l}\text { Treatment after } \\
\text { failure }\end{array}$ & 2 & 1.2 \\
\hline Transfer in & 7 & 4.3 \\
\hline \multicolumn{3}{|l|}{ Type of TB } \\
\hline $\begin{array}{l}\text { Smear positive } \\
\text { pulmonary }\end{array}$ & 73 & 45.1 \\
\hline $\begin{array}{l}\text { Smear negative } \\
\text { pulmonary }\end{array}$ & 66 & 40.7 \\
\hline Extra pulmonary & 23 & 14.2 \\
\hline \multicolumn{3}{|l|}{ Treatment Outcome } \\
\hline Cured & 44 & 27.2 \\
\hline Treatment completed & 59 & 36.4 \\
\hline Treatment failure & 2 & 1.2 \\
\hline Not evaluated & 51 & 31.5 \\
\hline Died & 6 & 3.7 \\
\hline
\end{tabular}

Prevalence of Tuberculosis: During the study period, 162 TB cases were registered and the overall average prevalence was found to be 32 per 1538 (2139 per 100,000) inmates. Higher TB prevalence was observed in the year of September 2011-August 2012 which was 2553 per 100,000 inmates. Then after this year, the prevalence was declining across the years (Table 2).

Tuberculosis treatment outcomes among inmates of Debrebirhan prison: Treatment outcome of 162 patients with tuberculosis who were registered at Debrebirhan prison health center during the five years period were analyzed. While 103(63.42\%) had successful treatment outcome (favorable treatment outcome), $59(36.45 \%)$ had poor treatment outcome (unfavorable treatment outcome). From the 162 TB patients, forty-four $(27.2 \%)$ were cured, $59(36.42 \%)$ had completed treatment, $2(1.24 \%)$ were treatment failure, $6(3.72 \%)$ died, 51(31.49\%) were not evaluated (either transferred out or released before completing their treatment). The highest treatment success, $15.43 \%$, was recorded in September 2011-August 2012 while the lowest, $10.50 \%$ was observed in September 2010-August 2011. On the other hand, 2(1.2\%), 51(31.5\%) and $6(3.7 \%)$ were treatment failure, not evaluated and died, respectively (Table 3 ).

While the maximum cured patients with TB, $12(7.41 \%)$, was registered in September 2013August 2014, the minimum 5(3.09\%) was recorded in September 2010-August 2011. Patients who completed their treatment slightly increased from 7.41\% in September 2010-August 2011 to $9.26 \%$ in September 2011-August 2012. However, there was a decrement to $8.02 \%$ in September 2012-August 2013 (Table 3).

DOI: http://dx.doi.org/10.4314/ejhs.v28i3.13 
Table 2: Prevalence of TB in Debrebirhan prison, North Shoa Ethiopia; September 2010 - August 2015 $(\mathrm{n}=162)$

\begin{tabular}{cccc}
\hline Year & $\begin{array}{c}\text { Number of } \\
\text { inmates }\end{array}$ & $\begin{array}{c}\text { All TB cases: } \\
\text { N (\%) }\end{array}$ & $\begin{array}{c}\text { Prevalence (per 100,000 } \\
\text { inmates) }\end{array}$ \\
\hline September 2010-August 2011 & 1203 & $29(17.9)$ & 2411 \\
September 2011- August 2012 & 1410 & $36(22.2)$ & 2553 \\
September 2012- August 2013 & 1682 & $38(23.5)$ & 2259 \\
September 2013- August 2014 & 1701 & $33(20.4)$ & 1940 \\
September 2014- August 2015 & 1695 & $26(16.0)$ & 1534 \\
$\quad$ Total & $\mathbf{7 6 9 1}$ & $\mathbf{1 6 2} \mathbf{( 1 0 0 . 0 )}$ & $\mathbf{1 0 6 9 7}$ \\
\hline
\end{tabular}

Table 3: Treatment outcomes across the years for all cases of tuberculosis in Debrebirhan prison, North Shoa Ethiopia; September 2010 - August 2015 (n = 162)

\begin{tabular}{cllllll}
\hline & \multicolumn{4}{c}{ Treatment outcome, N (\%) } & \multirow{2}{*}{$\begin{array}{c}\text { Total } \\
\text { N (\%) }\end{array}$} \\
\cline { 2 - 5 } Year of Treatment & Cured & $\begin{array}{l}\text { Treatment } \\
\text { competed }\end{array}$ & $\begin{array}{l}\text { Treatment } \\
\text { failure }\end{array}$ & $\begin{array}{l}\text { Not } \\
\text { evaluated }\end{array}$ & Died & \\
\hline Sep 2010- Aug 2011 & $5(3.09 \%)$ & $12(7.41 \%)$ & $1(0.62 \%)$ & $9(5.56 \%)$ & $2(1.24 \%)$ & $29(17.90 \%)$ \\
Sep 2011- Aug 2012 & $10(6.17 \%)$ & $15(9.26 \%)$ & $0(0.00 \%)$ & $10(6.17 \%)$ & $1(0.62 \%)$ & $36(22.22 \%)$ \\
Sep2012- Aug 2013 & $10(6.17 \%)$ & $13(8.02 \%)$ & $1(0.62 \%)$ & $12(7.41 \%)$ & $2(1.24 \%)$ & $38(23.46 \%)$ \\
Sep 2013- Aug 2014 & $12(7.41 \%)$ & $8(4.94 \%)$ & $0(0.00 \%)$ & $12(7.41 \%)$ & $1(0.62 \%)$ & $33(20.37 \%)$ \\
Sep 2014- Aug 2015 & $7(4.32 \%)$ & $11(6.79 \%)$ & $0(0.00 \%)$ & $8(4.94 \%)$ & $0(0.00)$ & $26(16.05 \%)$ \\
Total & $44(27.2 \%)$ & $59(36.42 \%)$ & $2(1.24 \%)$ & $51(31.49 \%)$ & $6(3.72 \%)$ & $162(100.0 \%)$ \\
\hline
\end{tabular}

Note: Sep stands for September and Aug stands for August

Predictors of TB treatment outcome in prison: Multivariable logistic regression model was employed to explore the association between treatment outcome and potential predictor variables. Accordingly, area of residence before imprisonment, duration of imprisonment and previous TB history were found to have statistically significant association with $\mathrm{TB}$ treatment outcome of the prisoners. The odds of successful treatment outcome was 3.59 times $(\mathrm{AOR}=3.59 ; 95 \% \mathrm{CI}: 1.44-8.93)$ significantly higher among urban resident TB patients as compared to rural residents. Duration of imprisonment was significantly associated with treatment success where those patients imprisoned for two or less years had 3.67 times $(\mathrm{AOR}=3.67$; $95 \%$ CI: $1.53,8.78$ ) greater success of treatment outcome than those who were in prison for more than two years. Prisoners' age, HIV status and TB type did not show any statistically significant association with treatment outcomes (Table 4).

\section{DISCUSSION}

This study assessed the prevalence of tuberculosis and treatment outcomes of patients with tuberculosis among inmates of Debrebirhan prison, North Shoa, Ethiopia. It has been reported that prevalence rates of TB in prisons are usually higher than national averages (6). This was reflected in this study by the high prevalence rate of $\mathrm{TB}$ ranging from 1534 to 2553 per 100,000 inmates in the five years period. The overall TB prevalence in this prison was found to be 2,139 per 100,000 inmates which was much higher than the prevalence reported by WHO in 2015 for the general Ethiopian population, estimated to be 200 per 100,000 populations (1). The high TB prevalence rate observed in this study was also in line with the previous studies of TB prevalence in other prisons of Ethiopia and other countries. High TB prevalence was reported in ten years 
Table 4: Predictors of treatment outcomes of patients with TB in Debrebirhan prison, North Shoa Ethiopia; September 2010 - August 2015 ( $\mathrm{n}=162)$

\begin{tabular}{|c|c|c|c|c|}
\hline \multirow[t]{2}{*}{ Predictors } & \multicolumn{2}{|c|}{ Treatment outcome } & \multirow[t]{2}{*}{ COR $(95 \% \mathrm{CI})$} & \multirow[t]{2}{*}{$\operatorname{AOR}(95 \% \mathrm{CI})$} \\
\hline & $\begin{array}{l}\text { Successful } \\
\text { Outcome } \\
\text { N (\%) }\end{array}$ & $\begin{array}{c}\text { Poor } \\
\text { Outcome } \\
\text { N }(\%)\end{array}$ & & \\
\hline \multicolumn{5}{|c|}{ Age group (in years) } \\
\hline $15-24$ & $31(59.62)$ & $21(40.38)$ & 1.0 & 1.0 \\
\hline $25-34$ & $39(63.93)$ & $22(36.07)$ & $1.20(0.56,2.57)$ & $1.43(0.57,3.59)$ \\
\hline $35-44$ & $22(73.33)$ & $8(26.67)$ & $1.86(0.69,4.97)$ & $1.79(0.54,5.95)$ \\
\hline$\geq 45$ & $11(57.89)$ & $8(42.11)$ & $0.93(0.32,2.71)$ & $2.19(0.60,7.95)$ \\
\hline \multicolumn{5}{|l|}{ Educational status } \\
\hline$<$ Grade 5 & $35(46.05)$ & $41(53.95)$ & 1.0 & 1.0 \\
\hline Grades5-10 & $55(78.57)$ & $15(21.43)$ & $5.08(1.34-19.27) *$ & $2.36(0.99,5.61)$ \\
\hline$>$ Grade 10 & $13(81.25)$ & $3(18.75)$ & $4.29(2.08,8.89)$ & $2.72(0.61,12.36)$ \\
\hline \multicolumn{5}{|l|}{ Residence } \\
\hline Rural & $50(51.55)$ & $47(48.45)$ & 1.0 & 1.0 \\
\hline Urban & $9(13.85)$ & $56(86.15)$ & $6.62(2.95,14.86)^{*}$ & $3.59(1.44,8.93)^{*}$ \\
\hline \multicolumn{5}{|c|}{ Duration of Imprisonment } \\
\hline$>2$ years & $49(51.04)$ & 47(48.96) & 1.0 & 1.0 \\
\hline$\leq 2$ years & $10(15.15)$ & $56(84.85)$ & $5.84(2.67,12.77) *$ & $3.67(1.53,8.78) *$ \\
\hline \multicolumn{5}{|l|}{ TB history } \\
\hline Yes & $9(75.0)$ & $3(25.0)$ & 1.0 & 1.0 \\
\hline No & $50(33.33)$ & $100(66.67)$ & $6.0(1.56,23.15)^{*}$ & $1.52(1.03,23.78) *$ \\
\hline \multicolumn{5}{|l|}{ Type of TB } \\
\hline SPP & $25(38.36)$ & $48(61.640$ & 1.0 & 1.0 \\
\hline SNP & $24(36.36)$ & $42(63.64)$ & $0.91(0.45,1.83)$ & $1.03(0.43,2.45)$ \\
\hline $\mathrm{EP}$ & $10(43.48)$ & $13(56.52)$ & $0.68(0.26,1.76)$ & $0.91(0.30,2.72)$ \\
\hline \multicolumn{5}{|l|}{ HIV status } \\
\hline Positive & $4(66.67)$ & $2(33.33)$ & 1.0 & 1.0 \\
\hline Unknown & $16(33.33)$ & $32(66.67)$ & $4.0(0.66,24.21)$ & $2.67(0.29,24.72)$ \\
\hline Negative & $39(36.11)$ & $69(63.89)$ & $3.54(0.62,20.20)$ & $2.10(0.25,17.71)$ \\
\hline
\end{tabular}

*Significance at $\mathrm{p}<0.05$, COR: crude odds ratio, AOR: adjusted odds ratio, Cl: confidence interval

retrospective study of North Gondar Zone prison which ranged from 579/100,000 to 2623/100,000 prisoners (11). However, a relatively lower prevalence (458.1 per 100,000 inmates) was reported in Northern and Eastern Ethiopian prisons (13). This might be due to the difference in sample size. Similarly, high TB prevalence was also observed in prisons of other African countries such as South African with prevalence of $8772 / 100,000$ prisoners (12) and Ugandan prison with prevalence of $955 / 100,000$ inmates (14),
Tanzania $(4,000)$, Malawi $(1,080)$, and Zambia $(2,200)$ per 100,000 populations (15).

The trend of TB prevalence in this study showed that there was a steady decrement over the last four study periods except in September 2011August 2012. This might be associated with the decline of TB prevalence in the general population observed in Ethiopia in the last five years $(1,3)$. The national TB survey of 2010/2011 reported a TB prevalence of $277 / 100,000$ population (3), while in 2013 the prevalence of TB in the general

DOI: http://dx.doi.org/10.4314/ejhs.v28i3.13 
population was declined to $211 / 100,000$, then to $200 / 100,000$ in 2015(1).

The treatment success rate found in this study was $63.42 \%$ which is lower than that of WHO international target of at least $85 \%$ (1). It is also lower than the national TB treatment success target set in the fourth Health Sector Development Program, which is $90 \%$ to be achieved by $2014 / 15$ (16). The treatment success of this study is also moderately lower than the one done in Debre Berhan Hospital which was 79.4\% (9).

This study revealed that $44(27.2 \%)$ of the patients were cured, 59(36.42\%) treatment completed, 2(1.24\%) treatment failures (one of these was found to be MDR TB), 6(3.72\%) died, and $51(31.49 \%)$ not evaluated. In this study, the cure rate is lower than that of a study conducted in El Salvador prison which was found to be $90.0 \%$ (17). Another research conducted in Debre Berhan Hospital found that 203(20\%) and 813(80\%) patients were cured and treatment completed, respectively. The low treatment success rate could be explained by the high transferred-out rate $(31.5 \%)$ of the TB patients to another prison or being freed from prison before completing their treatment. Since there was no system to trace and follow the final treatment outcome of the transferred-out patients, their treatment outcome was not evaluated and there could be a chance that they might end-up with treatment failure or death. If treatment failure could be the outcome, development and spread of drug resistant TB to the community could be the immediate consequence (11).

The multivariable logistic regression of this study revealed that TB treatment outcome was associated with area of residence, duration of imprisonment and previous history of TB. The odds of successful treatment outcome was significantly higher among urban residents than among rural residents $(\mathrm{AOR}=3.59,95 \% \mathrm{CI}$ : 1.44 8.93) which might be due to the fact that patients from urban area might have better awareness on TB treatment $(18,19)$. Furthermore, patients who had lower duration of stay in the prison reported to have more favorable treatment outcomes $(\mathrm{AOR}=3.67,95 \%$ CI: 1.53-8.78) than their counterparts. This could be explained by the psychological distress, which may affect the adherence to the treatment being worse in prisoners who stayed longer in the prison than in those who stayed shorter $(6,20)$. A study conducted in Brazilian prisons showed that treatment category of TB was associated with treatment outcome of patients (21). Similar to this finding, one study conducted in an Ethiopian university hospital found that undergoing previous retreatment was significantly associated with treatment outcome (22).

Although this study has a significant input for researchers and policy makers, there is a limitation in that it was based on secondary data that it was not able to assess factors of TB treatment outcome that are related to the patients, the health care providers and the health service. This study revealed high prevalence of TB in Debrebirhan prison. It also revealed that the treatment success rate of tuberculosis patients was lower than the target set by the World Health Organization. Hence, the prison authority together with regional and/or national TB control programs should develop locally feasible interventions to reduce the transmission and establish efficient referral and contact tracing mechanisms for transferred-out cases. The direct observation therapy program should also be strengthened to improve the treatment success rate.

\section{REFERENCES}

1. World health organization. Global tuberculosis report. Geneva, Switzerland: WHO; 2015.

2. World health organization. Global tuberculosis report. Geneva, Switzerland: WHO; 2014.

3. Federal Ministry of Health of Ethiopia. National Population Based Tuberculosis Prevalence Survey. Addis Ababa, Ethiopia: MOH, July 2011.

4. Tuberculosis in Prisons: A Growing Public Health Challenge: World TB Day 2014 | U.S. Agency for International...-USAID. https://www.usaid.gov/what-we-do/global health/tuberculosis/world-tb-day-2014/ Mar 25, 2014. Retrieved on May 15, 2016.

5. Gebrecherkos T, Gelaw B, Tessema B. Smear positive pulmonary tuberculosis and HIV co-

DOI: http://dx.doi.org/10.4314/ejhs.v28i3.13 
infection in prison settings of North Gondar Zone, Northwest Ethiopia. BMC Public Health. 2016; 16:1091.

6. Terefe GF, Samuel YA. Prevalence of smear positive pulmonary tuberculosis and associated risk factors among prisoners in Hadiya Zone prison, Southern Ethiopia. BMC Res Notes. 2016; 9:201.

7. Federal Ministry of Health (FMOH). Why TB? Evaluating the National TB Control Program: Challenges and ways forward. Federal Ministry of Health $16^{\text {th }}$ National Annual Review Meeting Group Discussion. FMOH, DISEASE PREVENTION and CONTROL DIRECTORATE. Available at: http://www.moh.gov.et/documents/26765/0/Wh $\mathrm{y}+\mathrm{TB}+$

Evaluating + the + National $+\mathrm{TB}+\mathrm{Con}$ trol + Program + Challenges/57d0ad37-d93c-4830-9cce-

$60 \mathrm{dc} 6 \mathrm{f} 61181 \mathrm{~b}$ ? version=1.0. Accessed on 3 July 2017.

8. Shin S. S, A. D. Pasechnikov D, Gelmanova I. $Y$. Treatment outcomes in an integrated civilian and prison MDR-TB treatment program in Russia. INT $J$ TUBERC LUNG DIS. 2006; 10(4):402-408.

9. Tefera F, Dejene T, Tewelde T. Treatment Outcomes of Tuberculosis Patients at Debre Berhan Hospital, Amhara Region, Northern Ethiopia. Ethiop J Health Sci. 2016; 26 (1)).

10. Zenebe T, Tefera E. Tuberculosis treatment outcome and associated factors among smearpositive pulmonary tuberculosis patients in Afar, Eastern Ethiopia: a retrospective study. Braz $J$ Infect Dis. 2016; 20(6):635-636).

11. Moges B, Amare B, Asfaw F, Mulu A, Tessema B, Kassu A. High prevalence and poor treatment outcome of tuberculosis in North Gondar Zone Prison, Northwest Ethiopia. International Journal of Medicine and Medical sciences. 2013; 5(9): 425-429.

12. Mogoere S.P. Risk factors associated with tuberculosis at mangaung correctional centre: retrospective analysis [MPH Thesis]. Oct. 2013.

13. Ali S, Haileamlak A, Wieser A, Pritsch M, Heinrich N, Loscher T. Prevalence of Pulmonary Tuberculosis among Prison Inmates in Ethiopia, a Cross-Sectional Study. PLOS ONE. 2015; 10(12).
14. Schwitters A, Kaggwa M, Omiel P, Nagadya G, Kisa N, Dalal S. Tuberculosis incidence and treatment completion among Ugandan prison inmates. Int $J$ Tuberc Lung Dis, 2014; 18(7): 781-786.

15. Roy W. World prison population list: Institute for Criminal Policy Research: London; 2016. (http://www.prisonstudies.org/). Accessed on April 23, 2016.

16. Ministry of Health of Ethiopia. Health Sector Development Plan IV. Addis Ababa, Ethiopia: $\mathrm{MOH} ; 2010$.

17. Ayala G, Garay J, Aragon M, Decroo T, Zachariah R. Trends in tuberculosis notification and treatment outcomes in prisons: a countrywide assessment in El Salvador from 2009-2014. Rev Panam Salud Publica. 2016; 39(1):38-43.

18. Gebrezgabiher G, Romha G, Ejeta E, Asebe G, Zemene E, Ameni G. Treatment Outcome of Tuberculosis Patients under Directly Observed Treatment Short Course and Factors Affecting Outcome in Southern Ethiopia: A Five-Year Retrospective Study. PLOS ONE.2016; 11(2).

19. Muture BN, Keraka MN, Kimuu PK, Kabiru EW, Ombeka VO, Oguya F. Factors associated with default from treatment among tuberculosis patients in Nairobi province, Kenya: a case control study. BMC Public Health. 2011; 11:696. DOI: 10.1186/1471-2458-11-696.

20. Biadglegne F, Anagaw B, Debebe $\mathrm{T}$ et al. A retrospective study on the outcomes of tuberculosis treatment in Felege Hiwot Referral Hospital, Northwest Ethiopia. Int. J. Med. Med. Sci.2013; 5(2):85-91.

21. Ribeiro ML, Reis-Santos B, Riley LW, Maciel EL. Treatment outcomes of tuberculosis patients in Brazilian prisons: a polytomous regression analysis. Int $J$ Tuberc Lung Dis.2013; 17(11):1427-34.

22. Biruk M, Yimam B, Abrha H, Biruk S, Zewdu F. Treatment Outcomes of Tuberculosis and Associated Factors in an Ethiopian University Hospital. Hindawi Publishing CorporationVolume 2016, Article ID 8504629, 9 http://dx.doi.org/10.1155/2016/8504629. 